\title{
News on headache
}

Headache is one of the more common presenting symptoms in general practice and seems likely to remain so, but advances are being made in its management and some of these were reviewed at the 15th annual meeting of the American Association for the Study of Headache in Toronto last month. The focus was on the treatment of migraine concentrating on calcium channel blockers and biofeedback.

The discovery by a patient that propranolol was effective against his headache as well as his angina led to the use of beta blockers as a prophylactic against migraine. The success of this approach stimulated similar interest in the use of calcium channel blocking agents, which prevent arterial spasm, inhibit platelet aggregation, and block the release and the uptake of serotonin by platelets. Three different American groups presented reports, one on experimental work and two on therapeutic trials in migraine headache and in migrainous neuralgia. The preliminary results were encouraging, but the numbers of patients in the trials were small; clearly larger groups will have to be tested and various preparations of calcium blocking agents compared with one another and with a placebo.
Treatment with biofeedback is still in vogue in America, but investigators are now comparing different techniques which include electromyography, varying methods of relaxation, and cutaneous thermography. Reports at Toronto claimed benefits though one group used drugs in addition to biofeedback and found that propranolol may interfere with learning vascular control.

Keeping up with modern technology three American groups reported on the help the computer can provide to overcome the difficulty of history taking. There is still the hope, at least in the United States, that the computer can sort out "mixed headaches," in which the patient has a combination of migraine and tension headache. How the computer differentiates between the hesitant personality, the anxious patient, or the naturally slow person is by no means clear. The feeling among the British group of participants was that the cerebral computer was still better than microchips.

J N BLAU

Consultant Neurologist,

National Hospital,

London WC1N 3BG

\section{An editor of genius}

Postwar Britain was fortunate in having two editors of genius for its weekly medical journals, Hugh Clegg at the BMF and (Sir) Theodore Fox at the Lancet. Like the two other really great medical editors, Thomas Wakley and Ernest Hart in the previous century, outwardly Clegg and Fox seemed very different: the one stocky, mercurial, and not at his best in a public forum; the other tall and distinguished, urbane, and one of the wittiest speakers of his day. Their journals, too, reflected individual traditions: of the (often unpalatable) realities of medical politics, on the one hand, and of an attractive, undogmatic radicalism, on the other.

Nevertheless, there were many more similarities than differences: both wrote well, especially under pressure; both could tackle any topic in any part of their journals; and politically both bestrode the medical world like colossuses. Even today, much of the pattern of the National Health Service has arisen from a consensus resulting from the wide ranging discussions in both journals-whether in editorials, correspondence, or reports of debates-before the Bill was introduced. Though both journals gave clear leads, both were also careful to allow for all shades of opinion; both editors were, in Robertson Scott's phrase, "evangelists and keepers of other people's consciences," and, to be partisan, the problem must have been particularly difficult for Hugh Clegg-who had first of all to establish the independence of the $B M \mathcal{Y}$ and then to use it with responsibility. He did this, and more, broadening the base of the publishing house, introducing concepts such as statistics and ethics into medical articles, and forging firm international medical, journalistic, and educational links.

Happily, Sir Theodore Fox is still with us, alive and well; unhappily, Hugh Clegg died last week at the age of 83 (p 220). He liked to compare himself to his homonym: clegg-a gadfly, horsefly, or breeze; somebody who darted about and bit mildly but without lasting hurt. A better, if more fanciful, comparison would have been to a hedgehog, to use Isaiah Berlin's image. ${ }^{1}$ Comparing Tolstoy with Dostoevsky, Berlin divided writers and thinkers into those who relate everything to a single central vision, the hedgehogs, and those who pursue many ends, seizing on a vast variety of experiences and objects for their own worth, the foxes; thus, Berlin maintains, Plato, Nietzsche, and Ibsen were all hedgehogs, Aristotle, Goethe, and Pushkin all foxes. By this classification, Hugh Clegg was certainly a hedgehog. His central vision, to which he singlemindecily devoted 30 years, was of a strong independent publishing house, practising its independence within the framework of an organised and powerful trade union. That we, his successors, can accomplish this daily, enjoyably, and without hindrance, speaks much for Hugh Clegg's genius and foresight.

STEPHEN Lock

Editor, $B M \mp$

Archilochus: "The fox knows many things, but the hedgehog knows one big thing." Berlin I. The hedgehog and the fox. In: Berlin I. Russian thinkers. London: Hogarth Press, 1978. 